Article

\title{
Development of a Blended Learning Environment to Support Achievement of Graduate Outcomes through Optimal Learning in an Undergraduate Pharmacy Course
}

\author{
Alyson Brown and Helen Vosper * \\ School of Pharmacy and Life Sciences, Robert Gordon University, Aberdeen AB10 7GJ, UK; \\ E-Mail: alyson.brown@rgu.ac.uk \\ * Author to whom correspondence should be addressed; E-Mail: h.vosper@rgu.ac.uk; \\ Tel.: +44-1224-262-503; Fax: +44-1224-262-555.
}

Received: 18 July 2013; in revised form: 3 September 2013 / Accepted: 15 October 2013 /

Published: 30 October 2013

\begin{abstract}
The development of graduate attributes through health professional courses requires the opportunity to engage with learning and teaching activities that reflect the work-based role to which the student aspires. Such activities allow the contextualisation of discipline-specific knowledge, forging a critical understanding of the underpinning theory, and providing a firm foundation for the development of lifelong learning skills. A blended learning approach can be particularly valuable in supporting achievement of the learning outcomes in modules where performance is measured in terms of competency in work-based scenarios. An action research approach was taken to develop and evaluate a cardiovascular risk assessment as the basis for clinically and professionally relevant problem-based learning. Support for this was provided by means of blended learning including a number of online activities. Talking wall focus groups were used to evaluate the student experience, and this was combined with quantitative data regarding student examination performance. Student performance in the cardiovascular section of the examination paper was significantly higher than in other sections. Students reported very favorably on the use of this approach to support not only examination preparation, but also in terms of developing professional identity and enhancing employability skills.
\end{abstract}

Keywords: problem-based learning; work-based learning; constructive alignment; simulation; blended learning; feedforward; student achievement 


\section{Introduction}

Quality learning experiences require a curriculum which promotes the development of attributes that ultimately underpin wider society [1] in terms of equipping students with relevant employability skills. Robert Gordon University (RGU) is committed to supporting students in this way by working with both employers and professional, statutory and regulatory bodies to develop educational programmes which meet the needs of the economy and society [2]. In the case of the UK undergraduate Master of Pharmacy course (MPharm), the profession is represented by the General Pharmaceutical Council, which has shifted the emphasis of the curriculum towards the development of clinical competencies underpinned by a strong scientific grounding. The Educational Standards have been built around Miller's triangle as a pedagogical model [3], and in order to achieve the higher outcomes, the importance of Bruner's spiral curriculum is recognised [4]. The course-level outcomes (provided by the GPhC) are therefore articulated in terms of Miller's levels of "knows", "knows how", "shows how", and "does". Teaching and learning activities need to support students in demonstrating achievement at the appropriate level and the ways in which this is done must be clear within the course documentation. Fundamental to such an approach is an awareness that each piece of the undergraduate curriculum exists as part of a much larger whole. One of the major requirements, therefore, for a high quality student experience is genuine integration between science and practice.

The use of problem-based learning as a means of developing higher order educational outcomes is well documented and is used extensively within the MPharm course at RGU. This paper describes an attempt to use such an approach in a second year module with limited success, which led to an extensive review of practice, completely changing the Biomedical Sciences component of the curriculum. This change can be summarised as "an integrated approach to biomedical science teaching and learning informed by the clinical competencies required of a practicing pharmacist".

\subsection{The Need for Change: an Analysis of Learner Needs}

The critical trigger for this initiative was a poor examination performance in a second year clinical pharmacology and therapeutics module that seemed out of step with the overall results of the cohort. In order to gain a deeper understanding of the teaching and learning issues, it was important to build a picture of the characteristics of this particular cohort. Sources of information used included free-text comments received as part of the module evaluation questionnaires, which form part of annual course appraisal. The number of comments received in this academic session was particularly high, suggesting that the students felt very strongly. Furthermore, the negative comments were unlikely to be a "knee-jerk" response to poor results as the closing date for responses fell before the date of the final examination. Within these responses, common themes included a sense of dismay with the lack of clinical opportunity afforded them, alongside the recognition of the importance of such opportunities for contextualising their learning.

The cardiovascular system represents a huge chunk of the curriculum, and consequently tends to have multiple staff involved in its delivery. It is possible that this underpinned the frequently expressed view that the teaching appeared fragmented, with no sense of an overriding theme. This, combined with a perception of a lack of clarity regarding learning outcomes and assessment criteria, created a 
degree of anxiety about tackling the examinations in this module, a problem which appeared to be exacerbated by the assessment distribution, which was primarily at the end of the module, meaning there were very few performance indicators to guide student effort. In line with the sector $[5,6]$, feedback was generally considered to be lacking. Students were clear about the ways in which some of these problems might be addressed, not least through the provision of online supporting materials. The following comment from the module evaluation questionnaire makes it clear that one student saw a need to improve the delivery of all activities:

"Make [lectures and courseworks] more interactive or something to save us from complete boredom".

Most of these issues were corroborated by staff, and combined with the changes happening at the level of the profession, it could be seen that the need for review was compelling.

This new approach to teaching therefore grew from the convergence of a number of themes relating to teaching, learning and assessment:

- Lack of constructive alignment within a second year Clinical Pharmacology and Therapeutics module (CPT-1);

- A need for integration of science and practice;

- Need for providing students with opportunities to "engage with the professional context".

On completion of the cardiovascular component of CPT-1, students need to understand the risk factors that contribute to cardiovascular disease, which requires a truly translational approach: the basic science must be applied to the clinical setting and the need to gather clinical "evidence" requires a number of both technical and non-technical skills. In the 2005-6 academic session, problem-based learning had been introduced in an attempt to provide students with a clinically relevant context to support their learning, but this resulted in approximately half the students failing the May exam. On reflection, it could be seen that much of the evidence validating the use of PBL is derived from North American studies [7] where pharmacy students have undergraduate degrees, providing them with the firm knowledge base required for dealing with more complex situations. Furthermore, module appraisals revealed staff had been using the majority of the contact time to deliver "knowledge", expecting the students to develop higher-order skills on their own as part of directed study. It was clear that a new approach was required: while PBL was seen as an appropriate way to support student learning (articulating well with the practice modules later in the course which make much wider use of this method), the module in its existing form was not providing students with the necessary support for learning. It was felt that a blended learning method, including the use of online activities, offered the potential to support the knowledge acquisition required for developing the more complex skills reflected in the learning outcomes for this module. Although - compared to other disciplines - there is relatively little published information regarding blended learning approaches for Pharmacy, there is an increasing trend in this direction. Crouch (2009) [8] describes the delivery of an Advanced Cardiovascular Pharmacotherapy course in a US institution where the course team combined a mix of online and face-to-face activities, which was well-received by students. It is important to bear in mind that for the majority of UK students of pharmacy, the MPharm will be their first degree and thus they may well be less developed than their US counterparts with respect to study skills. 


\section{Experimental Section}

This study describes the response of the module team to an unexpectedly poor module performance and is therefore an action research approach. Overall, the review plan for the new module involved the following (See Figure 1):

- Biomedical sciences curriculum re-design, with a particular emphasis on the learning outcomes for CPT-1 and the other science modules in the early part of the course to ensure the effectiveness of the science teaching in underpinning the development of appropriate graduate attributes. This also included a change in the assessment strategy;

- The construction of suitable problem-based learning activities that not only support the development of general graduate attributes, but that also reflect the professional role to which the student is aspiring;

- The development of tools to help students to acquire knowledge and begin to integrate it as part of their directed study;

- Evaluation of the impact of the changes on module performance and other indicators of success.

Figure 1. Development and evaluation of PBL approach for Clinical Pharmacology and Therapeutics-1.

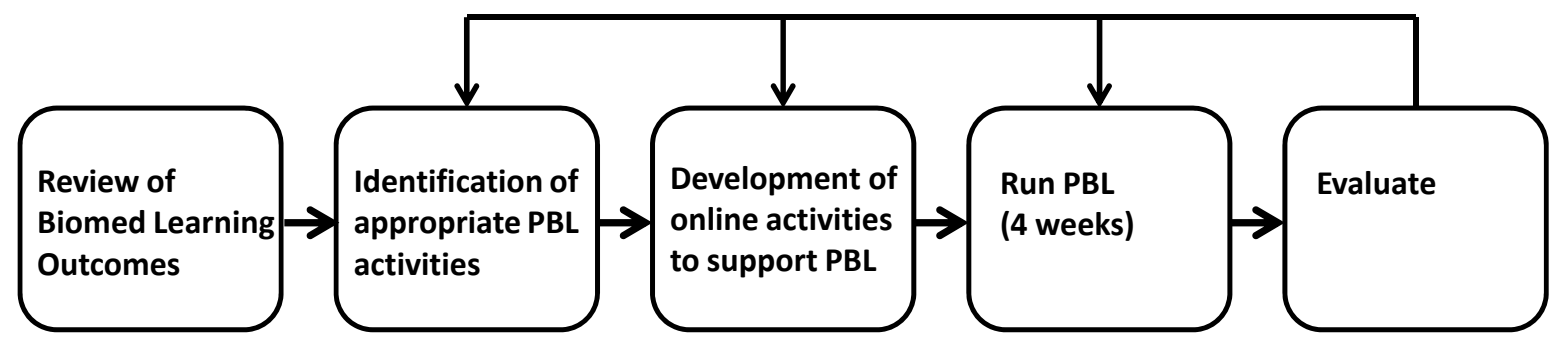

The first step was a "top-down" analysis of the content of the MPharm programme, beginning with a consideration of the role of the pharmacist, through the final-year practice-based modules and down to the underpinning science modules taught in the early years. This information was supplemented with findings from the Royal Pharmaceutical Society's "Fit for the future" study [9], and the so-called "Aston report," considered to be "a comprehensive and systematic assessment of current approaches to teaching, learning and assessment in UK schools of pharmacy [10]". This information was used to identify appropriate topics for new learning outcomes.

A similar approach was taken with the first year biology and physiology teaching (that theoretically underpins the later clinical modules) allowing introduction of fundamental concepts and their "iterative re-visiting" throughout the three modules. The scope of the learning outcomes in Clinical Pharmacology and Therapeutics is now large, ranging from skills and knowledge acquisition, right through to the more complex behaviors that characterise the graduate outcomes.

\subsection{Moving to a Blended Learning Approach: Developing an Online Learning Environment to} Support Students in Preparing for (and Learning from) Face-to-Face Activities

It was considered that a blended learning approach would be most suitable for delivering this module. The higher level outcomes describe the development of context-specific work-based skills, 
and therefore some sort of face-to-face delivery was necessary for this aspect. However, as far as the delivery of materials to support knowledge acquisition and the development of technical skills, the module team felt there was considerable scope for enhancement via an online approach. When moving from a face-to-face to an online (or blended) learning environment it is critical to avoid the danger of merely converting it into an electronic version of the face-to-face equivalent: rather than simply acting as a repository for content, there must be significant opportunity for students to interact with that content, with each other, and with staff. However, the module is long (running over two semesters) and intense; a separate research study carried out across the faculty, which included an audit of assessment distribution, revealed the second semester of second year to be relatively heavy with regard to the total amount of assessment. Consequently, the flexibility of an asynchronous approach to activities was preferred - this allows the learner control of access and pace, as well as location. Having completed the analysis of learner needs, the module was developed following the ADDIE instructional design model (analysis, design, development, implementation, and evaluation).

\subsection{Desired Behavioural Outcomes-Designing Suitable Problem-Based Learning Activities}

Ultimately the desired outcomes for this module include the acquisition (and demonstration) of work-based skills. These skills include the complex behaviours described in the course-specific graduate outcomes. Achievement of these "top level" outcomes requires the construction of suitable problem-based learning activities that reflect the work environment. Reducing cardiovascular morbidity and mortality is a key National Health Service (NHS) policy objective, and risk assessment is an essential part of current health strategy [11]. The community pharmacy is increasingly the setting for such procedures, and therefore teaching scenarios based around this were considered highly appropriate, while skills developed in such a setting are consistent with the development of appropriate graduate attributes. The risk assessment itself is based around the identification of both modifiable and non-modifiable risk factors, information acquired through a combination of patient history, and some simple near-patient testing. The results are used to calculate a 10-year risk of cardiovascular disease using an appropriate algorithm. The risk assessment activity was designed to run during courseworks over a four-week period. In the first two weeks, students are supported in developing the skills (both technical and non-technical) necessary to carry out the assessment. In the third week, the students get a "dry run" on a member of the teaching staff, before the final week where the coursework runs as a simulated risk assessment using volunteer members of non-teaching staff as patients. Over the first three weeks, students are encouraged to think about the scientific theory behind the clinical "decisions" they are making, and as part of the final week, after they have finished with the patients, they are invited to repeat their advice to a member of staff, but this time explaining the underpinning science. During this activity, it can be seen that students have to:

- Gather information from the patient;

- Make some degree of "diagnosis" (including interpretation of test results);

- Formulate a care plan including diet and lifestyle advice;

- Explain the science underpinning these clinical decisions. 
This format represents a reasonable structure for answering the summative coursework assessment (which involves gathering information from patient case notes) and for the essay questions in the final examination (which is case study-based). Students were therefore encouraged to use the four weeks of formative risk assessment to develop their own exam strategy based on this framework and supported by feedback at all stages from staff, providing a genuine constructive alignment. In later years, we began to film the sessions (including staff feedback), providing students with a lasting piece of feedback that could be revisited, providing a further feedforward element.

\subsection{The Development of Online Activities to Promote and Support Behavioural Outcomes}

An outcomes based approach to the module needs to be underpinned by a sound knowledge base in terms of the underlying physiology, pathology, and therapeutics of the cardiovascular system. In order to be able to apply this knowledge in the later work-based activities, the students also need to begin to explore how this knowledge can be applied to the workplace context. Quality online materials can fulfill these needs, and interactive ehandouts were designed to not only provide access to the material, but also to use targeted questioning to provoke student thinking.

Essentially staff need to encourage students to use the resources they already have, and combine this with helping them to identify resources which are currently lacking, while providing the support to enable them to develop in these new areas. In addition, we need to foster this development by providing appropriate tasks and responding with constructive feedback. Problem-based learning (PBL) can provide a good framework for this, and indeed the final cardiovascular risk assessment simulation is an example of this. PBL has been around since the mid-1960s, when it was first developed by Barrows at McMaster University [12]. Since its beginning, its use has expanded worldwide, although it tends to be more popular in the medical sciences, where it began. Essentially, the approach aims to help students "apply and integrate existing knowledge, while at the same time allowing them to identify and fill in gaps in their knowledge $[13,14]$ ". The material is delivered by presenting students with a "problem", and in the Medical Sciences_including Pharmacy_patient case-studies lend themselves particularly well to this [15]. The students, through self-study, then come up with possible answers to the problem. The viability of their arguments are then normally "tested" by some sort of "negotiation" phase - usually group work involving other students and a member of staff to facilitate the discussion by acting as the "intelligent questioner".

Such a method fully embraces the principles derived from a constructivist approach to learning [16]: it is consistent with the notion that knowledge is "constructed by the learner, based on previous knowledge and overall views of the world". Furthermore, in the words of Camp:

"Cognitive conflict stimulates learning and knowledge evolves though social negotiation and evaluation of the viability of individual understandings" [17].

Such experiences can be very challenging for a student, especially at this relatively early stage in the course. The interactive ehandouts that were developed began by supporting students in knowledge acquisition in ways that required them to take an active role. For example, the parameters that define the limits of the normal ranges for blood lipids show considerable variability depending on the guidelines that are used and other factors such as the presence or absence of co-morbidities. 
Students are thus encouraged to compile (using an appropriate evidence base) their own set of data that they will use later in the module as part of their actual risk assessment. This progressive, active construction of knowledge is then built on by introducing clinical problems of increasing complexity and demonstrating how a seven-step framework can be used to support the generation of reasonable answers. The ehandouts include links to websites, guidelines, videoclips and other interactive online resources, which can be used to acquire, test, and apply knowledge. One of the problems of using a blended approach is ensuring that students are engaging with the materials. A series of online quizzes (using QuestionMark Perception ${ }^{\mathrm{TM}}$ ) was developed. These quizzes contained multiple choice questions, although many of these were of the assertion-reason type, requiring students to integrate and apply their knowledge. The question bank was moderated by the module team and piloted with students from a previous cohort. Each question was assessed for item discrimination-score on the question was correlated with overall score on the quiz, thus allowing the module team to eliminate poor questions. The quizzes had the advantage of allowing students to test their knowledge and understanding, as well as allowing the module team to deal with common student errors (by including these as options in multiple choice type questions accompanied with appropriate feedback). In addition, students were required to enter their matriculation number which meant that non-participation could be picked up and dealt with long before the final examination. This interaction with online content was then used as a starting point for face-to-face contact during tutorials. Engagement with the online material allows students to come to a very clear understanding of their strengths and weaknesses which can be used to support further learning. In addition to this theoretical framework, the online environment allowed the module team to support practical skills development, in the form of online tutorials covering, for example, the measurement of blood pressure. The online activities formed what is referred to in the RGU MPharm as "directed study" and was not summatively assessed.

\subsection{Closing the Loop: Using the Online Environment to Provide Quality Feedback for Feedforward}

The culmination of the module is the simulated risk assessment. By the time the students reach this point, they have received considerable feedback on the supporting activities. Feedback on the final activity is given face-to-face. However, in recent years, the module team has moved to filming the risk assessment (complete with staff feedback). These clips are then uploaded onto the Virtual Learning Environment, for students to review at their leisure. This provides an opportunity for reflection, allowing them to judge for themselves their own developmental needs. This, combined with the staff feedback, can be used for feedforward to support future performance both in examinations and in the practice environment.

\subsection{Implementation and Evaluation}

Over the past six years, this approach to teaching has been evaluated using a mixed methods approach. Metrics (such as pass rate and mark) have been combined with staff and student feedback (through thematic analysis of student evaluation questionnaires, focus groups and "talking walls" [18]). This data has been enriched by input from external stakeholders such as external examiners and practising professionals, and has been used to modify the risk assessment each year. 


\subsection{Evaluation: Analysis Methodology}

The project was reviewed and received approval from the School Ethical Review Panel. Students were invited to participate in the evaluation stage of the project at the beginning of the cardiovascular coursework sessions. Written consent for participation was obtained. There were 137 students in this cohort and all consented to their involvement (see paragraph on "limitations"). In terms of demographics and achievement, this cohort was similar to previous years. Students were invited to write comments onto sticky notes and leave these on three posters headed "The overall experience", "Skills development", and "Learning." There were total of 137 in this cohort, and all were invited to participate at the beginning of the coursework sessions. Participation was not compulsory, and comments were transferred verbatim into an electronic record. Thematic analysis was selected as an appropriate method of data analysis as it offers a flexible approach that can yield different levels of complexity with regard to the data generated [19]. Essentially, a "realist" approach was taken, in that the analysis simply reports the explicit meanings of student comments, rather than looking for latent meaning. In determining the themes, attention was paid not only to frequency, but also to whether or not the data captured issues of importance to the research questions. The themes were identified by one researcher (HV) and confirmed by the second (AB). No discrepancies were identified between researchers.

\section{Results and Discussion}

Interestingly, one of the major outcomes of this piece of work relates to assessment. The purpose of the intervention was to improve performance in the final written exam and reduce attrition. By the academic session 2011-12, the failure rate had reduced from 50\% (in 2005) to 2\% [20]. Furthermore, performance in the cardiovascular questions was seen to be significantly higher than in other areas of the paper (73.5\% compared with 47.75\%; $p<0.05$ in May 2012). Staff on the module are of the opinion that student achievement in the cardiovascular section is adequately measured through the online and face-to-face activities described above. This raised the possibility of removing the written examination component, although it would obviously require a slight change to the delivery of the risk assessment activities in order to allow the assessment of individual students, rather than group performance.

With regard to the thematic analysis, many of the themes arising were connected to the workplace role and employability, suggesting that students were clear about the intended outcomes of the module and understood its relevance in respect of the development of professional identity. This is probably not surprising given that the broader aim of most students is to secure employment following completion of their course. The comments presented in the tables are considered by the authors to be representative of the total comments received. The comments were overwhelmingly positive, with the exception of those relating to the numbers of students in each group.

\subsection{Putting Knowledge/Skills/Theory into Practice}

According to Keiny (2002), quoted in [21], "to learn is to participate and contribute to the evolution of the communal practice". One interpretation of this in the higher education setting is that if teaching and learning activities are not set in the appropriate professional context, then learning in the true sense 
cannot occur. This offers a number of challenges for curriculum design, not least the need to provide work-based opportunities for students to apply (and thus contextualise) their knowledge. For healthcare courses, this provision would generally take the form of clinical placement, but such options are very limited for pharmacy students. Another potential issue is that this view challenges the more traditionalist concept that knowledge can exist independently of context, and that overt contextualisation can lead to the weakening of disciplinary knowledge and the undermining of a more scholarly approach to education. However, it could be argued that no knowledge is without context, and the challenge is more one of combining the abstract nature of theory with the "real" nature of the workplace environment, and of developing flexible students who are capable of this continual "recontextualisation" of their learning. It is critical that students are supported in transferring knowledge between contexts, and to understand that this is not the responsibility of the individual learner. Students who are effectively supported in this way are much more likely to recognise that workplace environments represent situations in which new knowledge in generated and, furthermore, provide opportunities for developing a critical understanding of that knowledge. Seeing such an establishment of a practice of learning in this way provides a strong foundation for the development of lifelong learning skills which are a key component of graduate attributes. It is clear from this study that students understand the value of these activities. Almost all participants commented favourably on the benefits of such an approach (Table 1):

Table 1. Theory into practice.

\begin{tabular}{l}
\hline "Puts what we have learnt into practice and shows how it is applied in a real-life situation." \\
\hline "Putting lecture knowledge into practice is really helpful for retaining the knowledge." \\
"Made me focus on an area of lecture material and learn it more in a practice environment \\
rather than just for lectures. This has given me a fuller understanding." \\
"It made me think about the information in terms of how I would relate it to the patient \\
rather than for the exam." \\
"Made me think in a practical way about different drugs and how to explain to patient so \\
was good preparation."
\end{tabular}

Comments such as these also reflect the value of active learning for integrating and applying knowledge [22]. Activities such as these which attempt to develop complex skills and behaviours typical of graduate attributes contribute significantly to student identity with their future role and this, in turn, acts to sustain their motivation for this ever-onward process of continual recontextualisation (Table 2).

Table 2. Skills development.

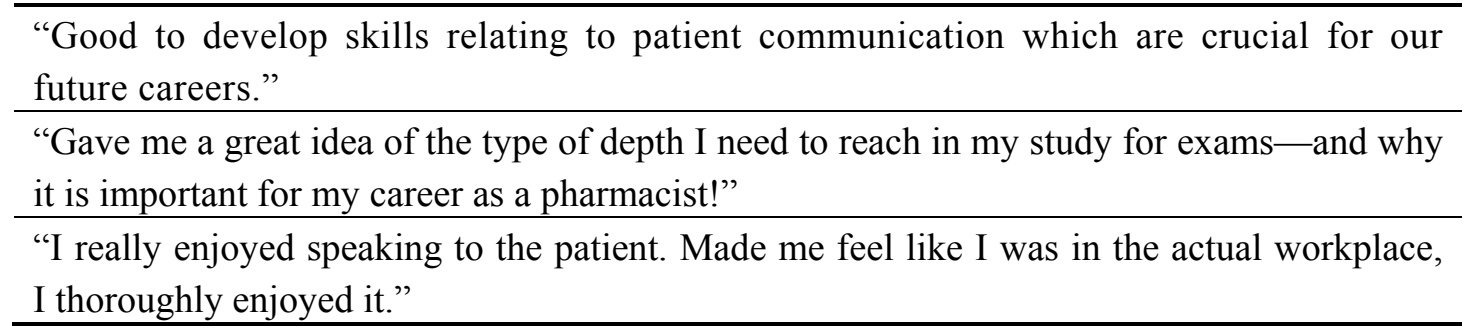




\subsubsection{Skills Development}

Vygotsky [23] recognised the need for students to be challenged, preferably in a way that requires them to perform just beyond their current ability level. However, for this challenge to provide an optimal learning environment, students need to be adequately equipped to deal with it. Staff must therefore provide students with what Mandigo and Holt [21] refer to as "support for competence". In the case of the cardiovascular risk assessment, these skills included practical and technical skills (measurement of blood pressure, accurate calculation of body mass index, etc.) and softer skills such as communication and consultation skills. Students appeared to recognise the value of this (Table 3):

Table 3. Development of non-technical skills.

"Great for developing interpersonal skills and for explaining conditions in 'lay man's terms""

"Good for developing communication skills and communicating with a real life patient."

"Helped think about how to talk to patients and how to approach them."

"Aided my in developing my skills in treating patients sensitively; Found it difficult saying to a patient that they were obese"

Interestingly, students seemed to appreciate that the activities contained within this module were part of a developmental processes and that true competency had not yet been achieved (Table 4):

Table 4. Identifying skill development needs.

"Develop skills we will need to master."

"Made us realise the skills that we have to work on, that communication skills are vital."

"Made us realise that we ALL need to improve our patient skills. I'm sure it'll improve with practice."

"Helped me to see areas that I need to work in but also gave me a bit of confidence with regard to dealing with blood pressure, through research via lecture notes and other materials."

"From practising to the actual CV risk assessment I have got progressively better at each skill e.g., getting blood pressure."

\subsubsection{Emotional Aspect}

Almost all the participants offered some reflection on the emotions experienced during the final simulation activity (Table 5). Many talked of prior anxiety that was eased by the actual experience, while others talked of increased confidence resulting from patient interaction. Many students commented on how much they had enjoyed what they perceived as a novel approach to teaching and learning. Staff also commented on how well the students had engaged with the final simulation activity: it was clear that a high level of psychological fidelity had been achieved.

Table 5. Emotional responses to the simulation activity.

\begin{tabular}{l} 
"Nervous to start with but once you got into it then really enjoyed a different way of learning." \\
"The session really helped me get over the fear of what I thought it was going to be like. It was \\
very interesting." \\
"Was more informal than I thought it would be; Overall it was fun and easier than expected." \\
"A bit nervewraking (sorry about spelling) but worth it - great to have interaction with patient so early on." \\
\hline
\end{tabular}




\subsubsection{Integration}

One of the aims of the new module approach was to improve integration between science and practice (horizontal integration), as well as between science modules (vertical). One of the difficulties here is that the molecular aspects of cell signalling can seem rather abstract and somewhat divorced from the reality of pharmacy practice. This can lead students to question the value of the science teaching, sometimes seeing success in these earlier modules as a "hoop to be jumped through", rather than underpinning the later clinical modules. Student comments (Table 6) suggest that the new activities help them to overcome this problem:

Table 6. Students appreciate the value with respect to integration.

\begin{tabular}{l}
\hline "Good opportunity to solidify the knowledge related to the cardiovascular system and its disease states." \\
"Made me look over and interconnect my CVS knowledge." \\
"Makes you think of CVD as a whole rather than individual problems." \\
"Also allowed us to see the material related to pharmacy practice." \\
"Makes you study all areas from previous years too for research." \\
\hline "Made me look over not just notes from this year but physiology notes from last year."
\end{tabular}

\subsubsection{Feedback for Feedforward}

To maximise the chance of student success, in addition to balancing challenge and skill in this way, teachers need to help students by providing immediate and constructive feedback, with support for responding to that feedback in such a way that it allows them to close the performance gap. Within this set of activities, feedback was provided at all stages, through a mixture of face-to-face and online mechanisms. While the frequency of comments does not necessarily indicate that any one theme is more important than another, it is worth noting that the highest frequencies occurred in comments relating to the feedforward aspects of the module activities (Table 7).

Table 7. Learning activities support future performance.

"Helped me prepare in advance for exam-this assessment made sure I actually covered everything in
the CV system and also helped me understand the type/style of questions asked."
"Has helped me revise through my CVS lectures, and therefore I think this risk assessment is a good
way in understanding the risk factors, more than just memorising the details."
"Putting knowledge into practice-I feel I understand more-a great head start to exams (-)"
"Excellent preparation for the exam as we had to learn information and understand it not only for the
assessment but which will come of use in the final exam too."
"Really good to actually deal with a real person like we will be in our future careers, think it helps
build confidence!"

Some of these comments suggest that students have used the feedback in order to set their own goals for their future learning - a keystone of the lifelong learning skills that students must develop. In addition, students make the point that was useful to see where they had gone wrong and this helped them make sure it didn't happen again suggesting that they recognise the value of using their errors as learning opportunities. 


\subsubsection{Students as Co-Creators}

Increasingly, traditional hierarchical models of higher education — with teacher/lecturer as expert—are being rejected in favour of a more collegial approach, where students are active participants in the whole learning process, including curriculum design. Taking an active role enhances the student experience and achievement at all levels: taking responsibility for their learning promotes a deeper engagement with the process, supporting them in becoming critical and analytical thinkers. Such an approach clearly supports the development of a framework which will support lifelong learning. It is also true that the student experience is quite different from that of the staff, and student views can offer a unique perspective on activities, offering increased scope for enhancement. As part of this project, student views as to how the process may be improved were actively sought, and most of the comments received related to the numbers of students in each group.

\subsubsection{Applicability to Other Courses}

A key element of the success of this approach has been the selection of the cardiovascular risk assessment as a focus for teaching and learning activities. Not only is this clinically and professionally highly relevant for all pharmacists, it requires the integration and application of almost the entire content of the cardiovascular section of the module. Cardiovascular risk management is a key issue for many health care professionals, and we are currently seeking to develop this as a basis for interprofessional learning opportunities. Nutrition and dietetics is one of the courses offered by the school and dietitians play an important role in supporting cardiovascular health, usually as part of a multi-disciplinary team and thus offers the chance for shared teaching and indeed assessment. The challenge for staff working in other fields is to identify similar activities that combine material from across a whole module.

\subsubsection{Limitations of the Study}

One of the main limitations of the study was the timing of the collection of student feedback. Students were asked to post comments immediately upon completion of the simulated risk assessment. This was to promote maximum engagement, which was indeed achieved, with all 137 students posting comments. However, it was clear that emotions were running high, with students feeling exhilarated at having "survived" what they perceived to be a stressful event. This may have accounted for the lack of negative comments - in future evaluations students should be given a "cooling down" period, giving them the opportunity to reflect more fully on their experience. This study did not include a formal evaluation of engagement with online activities. The module team observed participation, and used this to identify students who were either struggling with the activities or not engaging at all. In addition, "common student errors" were observed from the activities, and these were discussed within the coursework sessions. However, it may also have been of value to evaluate if engagement with online activities showed any link to grade outcome in the module, and this is an area for future work. Finally, as discussed above, the module team hope to make this risk assessment into the summative assessment for future students, and it was clear from this work that the student experience varied depended on the "patient" the group was allocated. Some "patients" were very healthy, whereas other had a range of 
relevant conditions, including diabetes and even overt heart disease. As Bray and colleagues [24] acknowledge, one of the problems facing staff is the development of robust, reliable and valid assessment tools, and this holds true for simulated activities as much as for the practice environment.

\section{Conclusions}

In summary, it can be seen that the activities described in this paper have had a profound effect on student achievement and their experience in a clinical pharmacology and therapeutics module. Students believe that this approach supports them in many ways: in terms of examination performance and skills development, as well as preparing them for their professional lives beyond the university. It is important to bear in mind that this is a student perception, although anecdotal evidence from past students now in practice suggests that these activities did support them in making the transition to the workplace. The next phase of this work is to include a longitudinal study which may provide evidence to support this. The use of quality online materials has freed up more contact time (in that lectures and courseworks are no longer used for didactic delivery), and prepared students to make the best of this time. It has also provided students with "real time" feedback on their progress and rendered non-participating students more visible, thus, allowing early intervention.

\section{Acknowledgments}

The authors would like to dedicate this paper to the memory of Yash Kumarasamy, the original leader on the cardiovascular risk assessment activity. They would also like to acknowledge the contributions of Stuart Cruickshank and Katie Maclure, as well as all the RGU staff who have given freely of their time as "patients" for the risk assessment.

\section{Conflicts of Interest}

The authors declare no conflict of interest.

\section{References}

1. HEA Strategic Plan 2012-16. Available online: http://www.heacademy.ac.uk/strategic-plan (accessed on 18 July 2013).

2. RGU. A Clear future. Available online: www.rgu.ac.uk/file/a-clear-future-for-a-leadinguniversity-in-a-new-era-pdf-340kb (accessed on 18 July 2013).

3. General Pharmaceutical Council. Standards for the initial education and training of pharmacists. Available online: http://www.pharmacyregulation.org/education/education-standards (accessed on 18 July 2013).

4. Bruner, J. The Process of Education; Harvard University Press: Cambridge, MA, USA, 1977.

5. Buckley, A. Making it count: Reflecting on the National Student Survey in the process of enhancement. Available online: http://www.heacademy.ac.uk/resources/detail/nss/Making_it_count (accessed on 18 July 2013).

6. Beaumont, C.; O’Doherty, M.; Shannon, L. Reconceptualising assessment feedback: A key to improving student learning? Stud. High. Educ. 2011, 36, 671-687. 
7. Schmidt, G. The process of problem-based learning. Med. Educ. 2011, 45, 792-806.

8. Crouch, M.A. An advanced cardiovascular pharmacotherapy course blending online and face to face instruction. Am. J. Pharm. Educ. 2009, 73, Article 51.

9. Royal Pharmaceutical Society of Great Britain (RPSGB). Fit for the Future; RPSGB: London, UK, 2004.

10. Wilson, K.; Jesson, J.; Langley, C.A.; Clarke, L.; Hatfield, K. MPharm Programmes: Where Are We Now? RPSGB: London, UK, 2005.

11. Horgan, J.M.P.; Blenkinsopp, A.; McManus, R.J. Evaluation of a cardiovascular disease opportunistic risk assessment pilot ('Heart MOT' service) in community pharmacies. J. Public Health 2010, 32, 110-116.

12. Barrows, H.S.; Tamblyn, R.M. Problem Based Learning: An Approach to Medical Education; Springer: New York, NY, USA, 1980.

13. Mackellar, A.; Silverthorne, J.; Thomas, S.; Price, G.; Cantrill, J. Problem-based learning in the fourth year of the MPharm at Manchester. Pharm. J. 2005, 274, 117-120.

14. Wood, D.F. ABC of learning and teaching in medicine: Problem based learning. Br. Med. J. 2003, 326, 328-330.

15. MacDonald, P.J. Selection of Health Problems for a Problem-Based Curriculum. In The Challenge of Problem Based Learning; Boud, D., Feletti, G., Eds.; St. Martin's Press: New York, NY, USA, 1991.

16. Honebein, P.; Duffy, T.M.; Foshman, B. Constructivism and the Design of Learning Environments: Context and Authentic Activities for Learning. In Designing Environments for Constructivist Learning; Duffy, T.M., Lowyk, J., Jonassen, D., Eds.; Springer: Berlin, Germany, 1993.

17. Camp, G. Problem-based learning; a paradigm shift or a passing fad? Available online: http://www.med-ed-online.org/f0000003.htm (accessed on 18 July 2013).

18. Parsell, G.; Gibbs, T.; Bligh, J. Three visual techniques to enhance interprofessional learning. Postgrad. Med. J. 1998, 74, 387-390.

19. Braun, V.; Clarke, V. Using thematic analysis in psychology. Qual. Res. Psychol. 2006, 3, 77-101.

20. Vosper, H.; Brown, A.; Mackenzie-Fraser, M.; Goodhand, K.; Joseph, S.; Diack, L. Simulation as a tool for supporting teaching, learning and assessment in an undergraduate pharmacy programme. In Compendium of Effective Practice in Higher Education; The Higher Education Academy: York, UK, 2013; Volume 2.

21. Mandigo, J.L.; Holt, N.L. Putting theory into practice: Enhancing motivation through OPTIMAL strategies. Avante 2002, 8, 21-29.

22. Rivkin, A.; Gim, S. Student preferences regarding teaching methods in a drug-induced diseases and clinical toxicology course. Am. J. Pharm. Educ. 2013, 77, doi:10.5688/ajpe776123.

23. Vygotsky, L. Mind in Society; Harvard University Press: Cambridge, MA, USA, 1978.

24. Bray, B.S.; Schwartz, C.R.; Odegard, P.S.; Hammer, D.P.; Seybert, A.L. Assessment of human patient simulation-based learning. Am. J. Pharm. Educ. 2011, 75, doi:10.5688/ajpe7510208.

(C) 2013 by the authors; licensee MDPI, Basel, Switzerland. This article is an open access article distributed under the terms and conditions of the Creative Commons Attribution license (http://creativecommons.org/licenses/by/3.0/). 